\title{
Mothers and fathers of children with epilepsy: gender differences in post-traumatic stress symptoms and correlations with mood spectrum symptoms
}

This article was published in the following Dove Press journal:

Neuropsychiatric Disease and Treatment

\author{
Claudia Carmassi ${ }^{1}$ \\ Martina Corsi' \\ Carlo Antonio Bertelloni' \\ Barbara Carpita' \\ Camilla Gesi' \\ Virginia Pedrinelli' \\ Gabriele Massimetti' \\ Diego Giampietro Peroni \\ Alice Bonuccelli² \\ Alessandro Orsini² \\ Liliana Dell'Osso' \\ 'Psychiatric Clinic, ${ }^{2}$ Pediatric \\ Clinic, Department of Clinical and \\ Experimental Medicine, University \\ of Pisa, Pisa, Italy
}

\begin{abstract}
Background: Post-traumatic stress disorder (PTSD) and post-traumatic stress spectrum have been recently applied to understand the impact of life-threatening disease or injury in one's child; nevertheless, scant data are available on a particular chronic illness such as epilepsy whose phenotypic expression is seizures, which are acute, sudden, and unpredictable manifestations. Subjects with bipolar disorders or with mood spectrum symptoms demonstrated to be more vulnerable to develop PTSD in the aftermath of a trauma.

Objectives: The main aim of this study was to evaluate post-traumatic symptoms among 134 parents of children with a diagnosis of epilepsy, followed at the outpatient neurologic unit of Department of Pediatrics in Santa Chiara Hospital in Pisa, as well as gender differences. The second aim of this study was to estimate the impact of lifetime mood spectrum on post-traumatic stress symptoms in the same study sample after fulfillment of the Trauma and Loss SpectrumSelf Report (TALS-SR) and the Mood Spectrum-Self Report (MOODS-SR) lifetime version. Results: Results showed $10.4 \%$ and $37.3 \%$ of PTSD full and partial, respectively. Demographic characteristics and clinical features of the study sample did not show any impact on stress symptomatology. Mothers presented higher rates at all Diagnostic and Statistical Manual of Mental Disorders (DSM)-5 PTSD symptoms' clusters except avoidance. Nevertheless, noteworthy correlations between post-traumatic symptomatology and mood spectrum symptoms detected with the self-report tools, emerged only in the subgroup of the fathers.

Conclusion: These findings corroborate the need to provide assistance to caregivers of pediatric patients and confirm the hypothesis that lifetime mood spectrum may have an impact on reaction to traumas.
\end{abstract}

Keywords: PTSD, post-traumatic stress spectrum, mood spectrum, DSM-IV, DSM-5, caregivers, children with epilepsy

\section{Introduction}

The characteristics of a traumatic event influence the development of post-traumatic stress disorder (PTSD), and although it is now recognized that traumas considered more serious are associated with a greater incidence and a worse course of PTSD, many authors have underlined the importance of so-called "minor" events (adopting a spectrum approach to trauma) in the development of a post-traumatic symptomatology, focusing the attention on individual experience vulnerability. ${ }^{1,2}$ In this regard, a severe or life-threatening illness in one's child can be one of the most emotionally and destabilizing events for a parent, ${ }^{3-5}$ so that subsequent revisions of the Diagnostic
Correspondence: Martina Corsi Psychiatric Clinic, Department of Clinical and Experimental Medicine, University of Pisa, Via Roma 67, 56100 Pisa, Italy

Tel +3950221 9760

Fax +3950221978

Email dott.martinacorsi@gmail.com 
and Statistical Manual of Mental Disorders (DSM) have progressively introduced illness in one's child among the events considered as traumatic.

Particular and apparently conflicting changes, however, occurred between the last two editions of the manual ( $D S M$-IV and DSM-5) on this topic. On one hand, the DSM-5, in fact, seems to emphasize the relevance of traumatic events occurred to close ones, when splitting criterion A into the following four sub-criteria that mostly (three out of four) refer to indirect exposure to events happening to others: criterion $\mathrm{A} 2$ refers to a trauma that the person has attended as a witness; criterion A3 refers to a trauma that the person has become aware of but that has happened to others; and criterion A4 contemplates extreme or repeated exposure to traumatic details because of specific work activities (eg, first responders who have collected human remains). On the other hand, the DSM-5 adopts a more restrictive approach to the illness of one's child: while the previous manual reported "a threatening disease in one's child" among traumatic events (criterion A), the DSM-5 specified that the event must be "a medical catastrophe concerning one's child", a condition that endangers life at the moment. Consequently, the DSM-5 replaced a life-threatening illness with a medical catastrophe, so that while the former statement mainly highlighted the objective serious nature of the disease for one's child's health, the latest highlighted the need for the event to be sudden and dangerous, with major attention on the urgency and abruptness of the perceived threat. ${ }^{2,6}$

Literature on PTSD in parents and caregivers of pediatric patients has been focused on the impact of severe diseases mostly defined by a chronicity, such as cancer, type 1 diabetes, and to a lower extent, to epilepsy. ${ }^{7-10}$ One previous study specifically investigating PTSD found rates as high as $31.5 \%$ (according to DSM-IV-TR) among 77 mothers of epileptic children. ${ }^{8}$ In a sample of 99 parents, we recently reported rates as high as $9.1 \%$ of DSM-5 PTSD (12.1\% of mothers and $3 \%$ of fathers). ${ }^{6,11}$

Epilepsy, however, differs from the other chronic conditions because of the unpredictability of seizures, the absence of an absolute diagnostic test, and the stigma associated with this condition that are all characteristics that may render epilepsy potentially traumatic especially for a parent facing it for the first time in his/her own child. ${ }^{12,13}$ Parents most often attend child seizures due to their caregiving role and most of the time experience feelings of helplessness and inadequacy. ${ }^{14,15}$ Consistently, epilepsy is a disease characterized by a dual nature in which sudden and acute events, seizures, are incorporated in a chronic course with a completely unpredictable trend, especially in the cases of nonresponse to therapy. In the light of this, we believe that seizures and epilepsy, more in general, may fall under the definition of medical catastrophe required by $D S M-5 .{ }^{6}$

A relationship with interesting implications is the one between PTSD and bipolar disorders as well as mood spectrum symptoms. Bipolar patients, in fact, demonstrated to be more vulnerable to trauma and PTSD. ${ }^{16-19}$ In previous studies, exploring Italian PTSD patients, a correlation was found between lifetime subthreshold manic-hypomanic and depressive symptoms and both the likelihood of suicidal ideations or attempts. ${ }^{20,21}$

Rates of trauma exposure as high as $98 \%$ were reported in individuals with bipolar compared to $51 \%-61 \%$ of the general population. The National Comorbidity Survey (NCS) reported a lifetime diagnosis of PTSD in $38.8 \%$ of individuals with bipolar I disorder in contrast with $6.8 \%$ of the general population with more than double rates in women $(9.7 \%)$ with respect to men $(3.6 \%){ }^{22}$

Gender, in fact, is one of the most recognized and investigated pretraumatic risk factors for developing PTSD. Despite this evidence on gender differences in PTSD prevalence rates in the aftermath of traumas, only a few studies focused on gender differences that affect PTSD symptoms. ${ }^{23-26}$

To the best of our knowledge, no data have yet been reported for the relationship between mood spectrum symptoms and post-traumatic stress symptoms in caregivers of ill children. In this regard, the aim of the present study was to fulfill this gap estimating full and partial PTSD rates as well as possible correlations with mood spectrum symptoms among parents of children with epilepsy, followed at the outpatient neurologic unit of the Department of Pediatrics, University of Pisa. Particular attention was devoted to gender differences.

\section{Methods \\ Study sample}

Parents of children with a diagnosis of epilepsy followed at the outpatient neurologic pediatric unit of a major university hospital in central Italy (Section of Pediatric Neurology of the Azienda Ospedaliero-Universitaria Pisana, Pisa, Italy) between May 2015 and February 2016 were enrolled. A total of 100 couples paired for the same child were invited to join the study (200 people). All eligible subjects provided written informed consent.

The study sample was investigated by means of the Structured Clinical Interview modules for PTSD of DSM-5 (SCID-5). According to the literature on DSM-5 criteria, a Partial A PTSD diagnosis and a Partial B PTSD diagnosis 
were also considered by means of the fulfillment of three of the four or two of the four B-E symptomatological criteria, respectively. ${ }^{27}$

The SCID was administered by psychiatrists trained and certified in the use of the study.

Instruments, both the interview and the questionnaires, were performed during the execution of the child's electroencephalography (EEG) as it takes about an hour.

All subjects recruited also fulfilled the following two specific questionnaires, which explore post-traumatic stress spectrum symptoms and lifetime mood spectrum symptoms, respectively: the Trauma and Loss Spectrum-Self Report (TALS-SR) ${ }^{28,29}$ and the Mood Spectrum-Self Report (MOODS-SR) lifetime version. ${ }^{30}$ The study was conducted under the approval of the Ethics Committee of Area Vasta Nord Ovest Toscana, in accordance with the Declaration of Helsinki.

\section{Instruments and assessment}

The TALS-SR includes 116 items regarding the lifetime experience of a range of losses and/or traumatic events and lifetime symptoms, behaviors, and personal characteristics that might represent manifestations and/or risk factors for the development of a stress response syndrome. The instrument is organized into nine domains (further information and PDF of the tool is in www.spectrum-project.org). The responses to the items are coded in a dichotomous way (yes/no), and domain scores are obtained by counting the number of positive answers. In accordance with the aims of the study, all participants were asked to report symptoms related to their child's epileptic syndrome.

The internal consistency between the self-report (TALS-SR) and the structural clinical interview format (SCITALS) of the TALS always exceeded the threshold of 0.90 , defining a substantial reliability in all the domains. ${ }^{29}$

The MOODS-SR includes 140 items exploring mood spectrum symptoms, coded as present or absent for one or more periods of at least 3-5 days throughout the subject's lifetime. The items are organized into manic and depressive components (each one sub-typed into three domains exploring mood, energy, and cognition), as well as into a section that assesses disturbances in rhythmicity and vegetative functions, yielding a total of seven domains. The number of the mood-, energy-, and cognition-manic items endorsed by subjects makes up the "manic component" (62 items) while the sum of the mood-, energy-, and cognition-depressive items constitutes the "depressive component" (63 items). The "rhythmicity and vegetative functions" (29 items) explores alterations in the circadian rhythms and vegetative functions, including changes in energy, physical well-being, mental, and physical efficiency related to the weather and season and appetite, sleep, and sexual activities (further information and PDF of the tool is in www.spectrum-project.org).

The internal consistency between the self-report (MOODS-SR) and the interview format (SCI-MOODS) of the MOODS always exceeded the threshold of 0.88 , defining a substantial reliability in all the domains. ${ }^{30}$

\section{Statistical analyses}

The rates of endorsement of each DSM-5 diagnostic criteria as well as the TALS-SR and MOODS-SR mean scores were calculated in the overall sample and in the subgroups of mothers and fathers. In order to investigate gender differences, Chi-square test (or Fisher when appropriate) was used in the case of categorical variables and Student's unpaired $t$-test was used in the case of parametric variables.

Bivariate Spearman's correlation coefficients were computed to investigate possible associations between the TALS-SR domains and the MOODS-SR ones.

The statistical analyses were carried out using SPSS, Version 23.0.

\section{Results \\ Sample demographic and clinical characteristics}

A total of 100 couples paired for the same child were invited to join the study (200 people); of them, 138 (69\%) parents (91 [91\%] mothers and 47 [47\%] fathers), with a mean age of $42.4 \pm 7.4$ years, provided initial written informed consent. Among the whole sample, 134 (67\%) parents completed SCID-5 assessment for PTSD diagnosis (90 [90\%] mothers and 44 [44\%] fathers) with no significant gender difference between the two samples $(P=0.420)$ and only $77(57.5 \%$ of the recruited sample) parents (47 mothers and 30 fathers) and $70(52.2 \%$ of the recruited sample) parents (44 mothers and 26 fathers) also fulfilled the TALS-SR and the MOODS-SR, respectively.

We tried to increase the number of fathers by contacting them by phone as often they did not take children for the follow-up visits. Regarding mothers, the most frequent answer provided for dropping the study was the lack of time.

Sociodemographic characteristics of the overall sample, as well as divided by gender, are shown in Table 1.

\section{DSM-5 full and partial PTSD prevalence rates}

Endorsement rates of each of the DSM-5 PTSD criteria are shown in Table 2 besides full blown and partial PTSD rates. In particular, $14(10.4 \%)$ parents $(13.3 \%$ of the mothers 
Table I Sociodemographic and clinical characteristics of the overall sample (134), fathers (44) and mothers (90)

\begin{tabular}{|c|c|c|c|}
\hline & Total & Mothers & Fathers \\
\hline Age (years), mean $\pm S D$ & $42.4 \pm 7.4$ & $41.5 \pm 7.2$ & $44.3 \pm 7.4$ \\
\hline \multicolumn{4}{|l|}{ Education, ${ }^{a}$ n (\%) } \\
\hline Primary or secondary school & $40(29.4)$ & $27(30.0)$ & $13(28.3)$ \\
\hline High school & $76(55.9)$ & $51(56.7)$ & $25(54.3)$ \\
\hline Degree & $20(14.7)$ & $12(13.3)$ & $8(17.4)$ \\
\hline \multicolumn{4}{|l|}{ Job, ${ }^{a}$ n (\%) } \\
\hline Employed & $125(9 \mid .9)$ & $81(90.0)$ & $44(95.7)$ \\
\hline Unemployed & II (8.I) & $9(10.0)$ & $2(6.3)$ \\
\hline \multicolumn{4}{|l|}{ Number of children, ${ }^{b} \mathrm{n}(\%)$} \\
\hline 1 & $47(35.3)$ & $70(77.8)$ & $37(86.0)$ \\
\hline$\geq 2$ (I with epilepsy) & $73(54.9)$ & II (I2.2) & $2(4.7)$ \\
\hline $\begin{array}{l}\geq 2 \text { ( }>\text { I with other chronic } \\
\text { diseases such as epilepsy and } \\
\text { diabetes) }\end{array}$ & $13(9.8)$ & $9(10.0)$ & $4(9.3)$ \\
\hline \multicolumn{4}{|c|}{ Type of events: convulsions and epilepsy, $n$ (\%) } \\
\hline Complex febrile convulsion & $7(5.1)$ & $4(4.4)$ & $3(5.1)$ \\
\hline Focal cryptogenic/idiopathic seizure & $55(39.9)$ & $33(36.3)$ & $22(39.9)$ \\
\hline Focal symptomatic seizure & $14(10.1)$ & $7(7.7)$ & $7(10.1)$ \\
\hline $\begin{array}{l}\text { - Generalized cryptogenic/ } \\
\text { idiopathic seizure }\end{array}$ & $48(34.8)$ & $37(40.7)$ & II (34.8) \\
\hline - Generalized symptomatic seizure & $14(10.1)$ & $10(11.0)$ & $4(10.1)$ \\
\hline \multicolumn{4}{|l|}{ Type of seizure, ${ }^{b} n(\%)$} \\
\hline Tonic-clonic & $42(31.6)$ & $30(33.3)$ & $12(27.9)$ \\
\hline Others (eg, absence) & $91(68.4)$ & $60(66.7)$ & $31(72.1)$ \\
\hline \multicolumn{4}{|c|}{ Number of seizures (lifetime), ${ }^{\mathrm{a}} \mathrm{( \% )}$} \\
\hline I or 2 seizures & $61(44.8)$ & $37(40.6)$ & $12(3 \mid .1)$ \\
\hline$>2$ & $75(55.1)$ & $54(59.4)$ & $31(68.9)$ \\
\hline \multicolumn{4}{|c|}{ Parents' psychiatric comorbidity, n (\%) } \\
\hline Mood disorder & $7(5.0)$ & $6(6.5)$ & $\mathrm{I}(2.1)$ \\
\hline Panic disorder & $7(5.0)$ & $7(7.7)$ & 0 \\
\hline Generalized anxiety & $4(2.9)$ & $4(4.4)$ & 0 \\
\hline
\end{tabular}

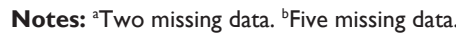

and $4.5 \%$ of the fathers, $P=0.143$ ) reported a diagnosis of PTSD according to $D S M-5$ criteria. A partial PTSD was detected in $50(37.3 \%)$ subjects with a significant difference between mothers and fathers (43.3 and $25.0 \%$ respectively, $P=0.039$ ).

Statistically significant gender differences also emerged in the endorsement rates of criterion B (intrusion symptoms)
( $P=0.047$ ), criterion $\mathrm{D}$ (negative alterations in cognitions and mood) $(P=0.010)$, and criterion $\mathrm{E}$ (alterations in arousal and reactivity) $(P<0.001)$ (Figure 1$)$.

Stratifying the sample both on demographic characteristics (education, occupation, number of children, and psychiatric comorbidity) and clinical features of children's disease (type of epilepsy, type of seizures, and number of seizures), no significant difference in the post-traumatic symptomatology emerged.

\section{TALS-SR and MOODS-SR rates of endorsement and correlations}

Mothers reported significant higher endorsement rates with respect to fathers in the following TALS-SR domains: "reactions to losses or upsetting events" $(P=0.035)$ and "re-experiencing" $(P=0.037)$. No gender differences emerged in the MOODS-SR domains' scores (Table 3).

Computation of the bivariate correlation coefficients showed moderate-to-good significant positive correlations between TALS-SR domain IX (personal characteristics/ risk factors) and MOODS-SR domain IV (manic energy), TALS-SR domain II (grief reactions) and MOODS-SR domain VI (manic cognition), TALS-SR total scores and MOODS-SR domain VI (manic cognition), and TALS-SR and MOOD-SR total scores (Table 4). The last correlation was the only one that persisted in the subgroup of mothers (Table 5). In contrast, in the fathers subgroup emerged several positive associations, particularly the following three strong associations: first, between TALS-SR domain IX (personal characteristics/risk factors) and MOODS-SR domain II (manic mood); second, between TALS-SR domain IX (personal characteristics/risk factors) and MOODS-SR domain IV (manic energy); and third, between TALS-SR total score and MOODS-SR total score (Table 6).

\section{Discussion}

Our results confirm some of our previous data ${ }^{6}$ showing $\sim 10 \%$ of parents of epileptic children reporting a diagnosis of PTSD,

Table 2 Full blown and partial PTSD rates $(A, B$, and $A+B)$ and endorsement of symptomatological DSM-5 criteria in the overall sample and divided by gender

\begin{tabular}{llllllllll}
\hline & $\mathbf{N}$ & $\begin{array}{l}\text { PTSD, } \\
\mathbf{n}(\%)\end{array}$ & $\begin{array}{l}\text { Partial A } \\
\text { PTSD }^{\mathbf{a}}, \mathbf{n}(\%)\end{array}$ & $\begin{array}{l}\text { Partial B } \\
\text { PTSD }^{\mathbf{b}}, \mathbf{n}(\%)\end{array}$ & $\begin{array}{l}\text { Partial PTSD } \\
(\mathbf{A}+\mathbf{B}), \mathbf{n}(\%)\end{array}$ & $\begin{array}{l}\text { Criterion B } \\
\text { fulfilled, } \mathbf{n}(\%)\end{array}$ & $\begin{array}{l}\text { Criterion C } \\
\text { fulfilled, } \mathbf{n}(\%)\end{array}$ & $\begin{array}{l}\text { Criterion D } \\
\text { fulfilled, } \mathbf{n}(\%)\end{array}$ & $\begin{array}{l}\text { Criterion E } \\
\text { fulfilled, } \mathbf{n}(\%)\end{array}$ \\
\hline Total & 134 & $14(10.4)$ & $23(17.2)$ & $27(20.1)$ & $50(37.3)$ & $83(61.9)$ & $34(25.4)$ & $28(20.9)$ & $63(47.0)$ \\
Mothers & 90 & $12(13.3)$ & $20(22.2)$ & $19(21.1)$ & $39(43.3)$ & $61(67.8)$ & $26(28.9)$ & $25(27.8)$ & $51(56.7)$ \\
Fathers & 44 & $2(4.5)$ & $3(6.8)$ & $8(18.2)$ & $11(25.0)$ & $22(50.0)$ & $8(18.2)$ & $3(6.8)$ & $12(27.3)$ \\
P-value & 0.143 & 0.048 & 0.867 & 0.039 & 0.047 & 0.181 & 0.010 & 0.001 \\
\hline
\end{tabular}

Notes: ${ }^{\text {aPartial }} \mathrm{A}=$ three DSM-5 symptomatological criteria fulfilled. ${ }^{\mathrm{b}}$ Partial $\mathrm{B}=$ two $D S M-5$ symptomatological criteria fulfilled.

Abbreviations: DSM, Diagnostic and Statistical Manual of Mental Disorders; PTSD, post-traumatic stress disorder. 


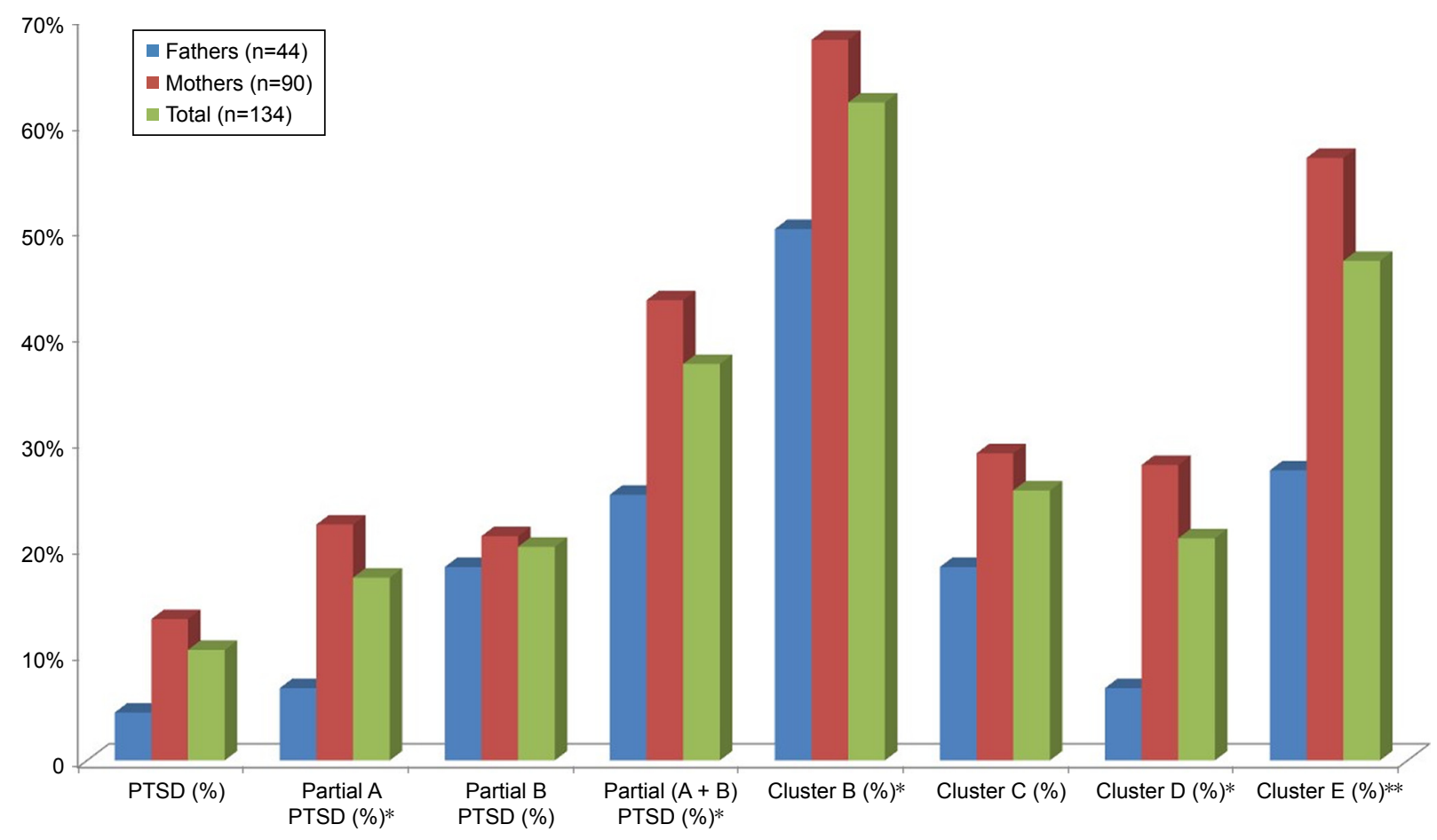

Figure I DSM-5 full and partial PTSD rates in the total sample and divided by gender.

Notes: $* P \leq 0.5$. $* * P \leq 0.01$.

Abbreviations: DSM, Diagnostic and Statistical Manual of Mental Disorders; PTSD, post-traumatic stress disorder.

Table 3 TALS-SR and MOODS-SR total and domain scores (mean \pm SD) in the total sample and divided by gender: mothers and fathers

\begin{tabular}{|c|c|c|c|c|}
\hline \multirow[t]{2}{*}{ TALS-SR } & $\begin{array}{l}\text { Total, } \\
\text { mean } \pm \text { SD } \\
\end{array}$ & $\begin{array}{l}\text { Mothers, } \\
\text { mean } \pm \text { SD } \\
\end{array}$ & $\begin{array}{l}\text { Fathers, } \\
\text { mean } \pm \text { SD } \\
\end{array}$ & P-value* \\
\hline & $\mathrm{n}=\mathbf{7 7}$ & $n=47$ & $n=30$ & \\
\hline (I) Loss events & $2.94 \pm 1.93$ & $3.10 \pm 1.82$ & $2.7 \pm 2.10$ & 0.174 \\
\hline (II) Grief reactions & $6.64 \pm 5.02$ & $7.10 \pm 5.32$ & $5.9 \pm 4.51$ & $0.28 \mathrm{I}$ \\
\hline (III) Potentially traumatic events & $3.31 \pm 1.88$ & $3.25 \pm 1.96$ & $3.4 \pm 1.79$ & 0.812 \\
\hline (IV) Reactions to losses or upsetting events & $5.31 \pm 3.15$ & $5.91 \pm 3.20$ & $4.37 \pm 3.20$ & 0.031 \\
\hline (V) Re-experiencing & $2.09 \pm 2.14$ & $2.47 \pm 2.35$ & $1.5 \pm 1.65$ & 0.037 \\
\hline (VI) Avoidance and numbing & $1.68 \pm 2.06$ & $1.79 \pm 2.16$ & $1.53 \pm 1.92$ & 0.601 \\
\hline (VII) Maladaptive coping & $0.24 \pm 0.49$ & $0.30 \pm 0.50$ & $0.167 \pm 0.46$ & 0.255 \\
\hline (VIII) Arousal & $1.35 \pm 1.62$ & $1.40 \pm 1.68$ & $1.26 \pm 1.55$ & 0.719 \\
\hline (IX) Personality characteristics/risk factors & $0.81 \pm 1.08$ & $0.8 \pm 0.87$ & $0.83 \pm 1.37$ & 0.923 \\
\hline Total & $24.4 I \pm I 3.08$ & $26.14 \pm 13.43$ & $21.70 \pm 12.25$ & 0.139 \\
\hline \multirow[t]{2}{*}{ MOODS-SR } & $\begin{array}{l}\text { Total, } \\
\text { mean } \pm \text { SD }\end{array}$ & $\begin{array}{l}\text { Mothers, } \\
\text { mean } \pm \text { SD }\end{array}$ & $\begin{array}{l}\text { Fathers, } \\
\text { mean } \pm \text { SD }\end{array}$ & $P$-value* \\
\hline & $n=70$ & $n=44$ & $n=26$ & \\
\hline (I) Depressive mood & $4.06 \pm 4.42$ & $4.11 \pm 4.39$ & $3.96 \pm 4.58$ & 0.891 \\
\hline (II) Manic mood & $4.66 \pm 3.37$ & $4.50 \pm 3.41$ & $4.92 \pm 3.35$ & 0.616 \\
\hline (III) Depressive energy & $0.89 \pm 1.44$ & $0.98 \pm 1.50$ & $0.73 \pm 1.34$ & 0.493 \\
\hline (IV) Manic energy & $1.24 \pm 1.66$ & $1.25 \pm 1.64$ & $1.23 \pm 1.72$ & 0.963 \\
\hline (V) Depressive cognition & $2.60 \pm 3.29$ & $3.09 \pm 3.52$ & $1.77 \pm 2.70$ & 0.105 \\
\hline (VI) Manic cognition & $2.60 \pm 2.76$ & $2.75 \pm 3.03$ & $2.35 \pm 2.27$ & 0.559 \\
\hline (VII) Rhythmicity & $7.10 \pm 4.46$ & $7.73 \pm 4.42$ & $6.04 \pm 4.39$ & 0.127 \\
\hline Total & $23.14 \pm 13.98$ & $24.4 I \pm 13.78$ & $21.00 \pm 14.34$ & 0.334 \\
\hline
\end{tabular}

Notes: *Evaluated by unpaired $t$-test. Statistically significant values are shown in bold.

Abbreviations: MOODS-SR, Mood Spectrum-Self Report; TALS-SR, Trauma and Loss Spectrum-Self Report. 


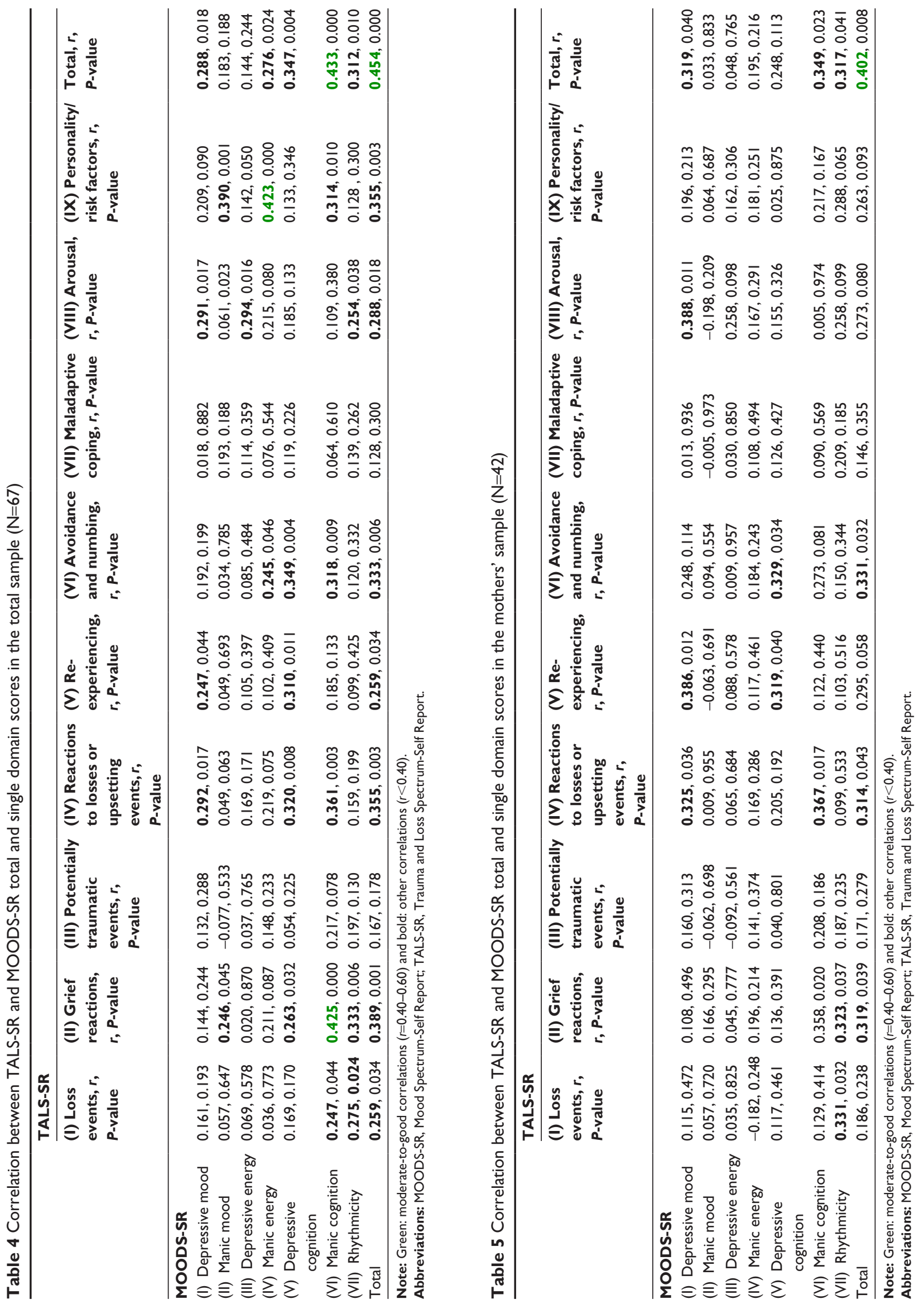




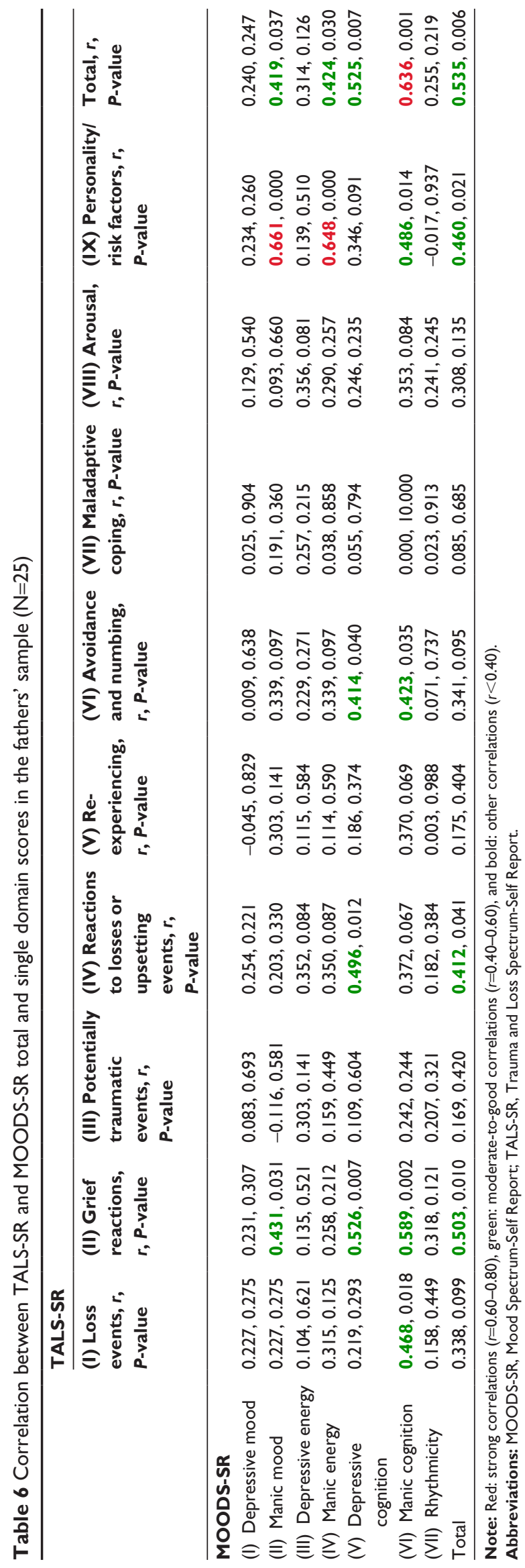

with a further $40 \%$ of parents endorsing criteria for partial PTSD. Intrusion symptoms and distressing memories also represented the most frequent symptoms in parents exposed to this kind of potentially traumatic event. It is interesting to note that the frequency of the partial forms of PTSD is perfectly in line with the data that has emerged in previous studies on parents of children with acute or chronic diseases. Farley et al, ${ }^{31}$ investigating parents of children with heart transplants, showed rates as high as $40 \%$ of partial PTSD; consistently; Poder et a $\mathrm{a}^{132}$ reported similar rates among parents of neoplastic children. Our results seem to corroborate the importance of subjective impact of the seizure, rather its objective severity, in order to trigger post-traumatic stress symptoms in the caregiving parents as no statistically significant relationship emerged between post-traumatic stress spectrum symptoms and the clinical characteristics related to epileptic disease, such as type of epilepsy (idiopathic/cryptogenic and symptomatic forms) and type and number of seizures. There were no statistically significant correlations between arousal domain and number of seizures and this was surprising as we expected that repeated exposure, as witnesses, of parents to seizures could increase alarm responses and thus affect arousal symptoms. Consistently, Lindahl Norberg et al ${ }^{33}$ evidenced how disease variables such as infant prognosis and the presence of a relapse in the clinical history did not impact on PTSD rates among parents of children with cancer.

An increased risk also emerged in the mothers with respect to fathers. In particular, mothers presented statistically significant higher rates of endorsement in the majority of the PTSD nuclear symptom clusters, such as intrusion symptoms, negative alterations in cognitions and mood, and alterations in arousal and reactivity, highlighting the increased vulnerability of female gender to consequences of trauma. In the US NCS Replication (NCS-R), Kessler et al reported PTSD rates as high as $6.8 \%$ according to DSM-IV with women $(9.7 \%)$ showing higher rates than men (3.6\%). Similar gender differences in PTSD rates have been reported in the aftermath of natural disasters, particularly earthquakes..$^{25,34}$ The present results seem to confirm these data even in the case of a severe illness in a child. The analysis of the post-traumatic stress spectrum through the TALS-SR supported these data as mothers presented higher rates of endorsement in all domains, reaching statistical significance in both the reactions to losses or upsetting events and re-experiencing domains.

The analysis of the correlations between traumatic spectrum and mood spectrum highlighted noteworthy consideration regarding the fathers, as we observed how very interesting data have emerged in this subgroup with 
strong correlations between the manic components of the MOODS-SR and the total score of the TALS-SR. This result is consistent with previous studies that found the presence of a manic state after even indirect trauma exposure to be a relevant risk factor for the development of PTSD. ${ }^{35,36}$ Our results may also lead to hypothesize a major role of hyperarousal as a possible mediator of this association. There are high levels of hyperarousal in manic states, and hyperarousal has been suggested as a possible mediator of the severity and course of PTSD symptoms over time. ${ }^{36,37}$ Epilepsy is a disease that presents a great impact on caregivers since seizures are characterized by features of scary visual impact (such as convulsions, tongue biting, and relaxation of the sphincters) which suggest an event unmanageable with potential danger for life and without any certainty about its duration. ${ }^{36,37}$ There is, in fact, a state of continuous alarm and apprehension which a parent must face together with the unpredictability of the disease that leads constantly to fear both for the safety of the child and for the repercussions on the whole family. ${ }^{12,38,39}$ A review on parental coping in the aftermath of childhood epilepsy reports how parents not only have to learn how to respond to this crisis situation and modify the daily activities of the family to accommodate the emotional and physical needs of themselves and their children, but they also have to learn to incorporate things such as medication, medical equipment, and periodic hospitalizations into their daily routine..$^{40,41}$

We might speculate that lifetime mood spectrum symptoms may reduce the difference between females and males in terms of vulnerability to the post-traumatic stress spectrum. A similar result was found by Dunn et $\mathrm{al}^{42}$ in 2012 where the presence of psychiatric comorbidity, especially depression or anxiety, flattened the differences between mothers and fathers in terms of PTSD rates.

Several limitations have to be taken into account when discussing our data. First is the limited sample size despite, to the best of our knowledge, this study has the largest sample of parents of children with epilepsy so far reported in literature. Second is the fact that this is a cross-sectional study without a control group and gender homogeneity that impairs the generalizability of the results. Last is the lack of information on the characteristics of epileptic illness of the children and on psychosocial comorbidities, in particular behavioral problems, which could have an impact on the TALS-SR scores.

\section{Conclusion}

Despite the limitations mentioned above, this study offers an important contribution to the detection of post-traumatic stress spectrum symptoms among parents of seriously ill children. Nevertheless, future work is needed to elucidate the relevance of recognizing these symptoms and the impact that they could have in the caregiving process of a particular and complex illness such as epilepsy.

\section{Disclosure}

The authors report no conflicts of interest in this work.

\section{References}

1. Dell'Osso L, Carmassi C, Massimetti G, Daneluzzo E, Di Tommaso S, Rossi A. Full and partial PTSD among young adult survivors 10 months after the L'Aquila 2009 earthquake: gender differences. J Affect Disord. 2011;131(1-3):79-83.

2. Friedman MJ, Resick PA, Bryant RA, Brewin CR. Considering PTSD for DSM-5. Depress Anxiety. 2011;28(9):750-769.

3. Barakat LP, Kazak AE, Meadows AT, Casey R, Meeske K, Stuber ML. Families surviving childhood cancer: a comparison of posttraumatic stress symptoms with families of healthy children. J Pediatr Psychol. 1997;22(6):843-859.

4. Kazak AE, Barakat LP. Brief report: parenting stress and quality of life during treatment for childhood leukemia predicts child and parent adjustment after treatment ends. J Pediatr Psychol. 1997;22(5): 749-758.

5. Landolt MA, Boehler U, Schwager C, Schallberger U, Nuessli R. Post-traumatic stress disorder in paediatric patients and their parents: an exploratory study. J Paediatr Child Health. 1998;34(6):539-543.

6. Carmassi C, Corsi M, Gesi C, et al. DSM-5 criteria for PTSD in parents of pediatric patients with epilepsy: what are the changes with respect to DSM-IV-TR? Epilepsy Behav. 2017;70(pt A):97-103.

7. Bruce M. A systematic and conceptual review of posttraumatic stress in childhood cancer survivors and their parents. Clin Psychol Rev. 2006; 26(3):233-256.

8. Cabizuca M, Marques-Portella C, Mendlowicz MV, Coutinho ES, Figueira I. Posttraumatic stress disorder in parents of children with chronic illnesses: a meta-analysis. Health Psychol. 2009;28(3):379-388.

9. Cernvall M, Alaie I, von Essen L. The factor structure of traumatic stress in parents of children with cancer: a longitudinal analysis. $J$ Pediatr Psychol. 2012;37(4):448-457.

10. Horsch A, McManus F, Kennedy P. Cognitive and non-cognitive factors associated with posttraumatic stress symptoms in mothers of children with type 1 diabetes. Behav Cogn Psychother. 2012;40(4):400-411.

11. Iseri PK, Ozten E, Aker AT. Posttraumatic stress disorder and major depressive disorder is common in parents of children with epilepsy. Epilepsy Behav. 2006;8(1):250-255.

12. MacLeod JS, Austin JK. Stigma in the lives of adolescents with epilepsy: a review of the literature. Epilepsy Behav. 2003;4(2):112-117.

13. Bandstra NF, Camfield CS, Camfield PR. Stigma of epilepsy. Can J Neurol Sci. 2008;35(4):436-440.

14. De Souza EA, Nista CR, Scotoni AE, Guerreiro MM. Feelings and behaviors of parents of children with epilepsy. Arq Neuropsiquiatr. 1998;56(1):39-44.

15. Jones C, Reilly C. Parental anxiety in childhood epilepsy: a systematic review. Epilepsia. 2016;57(4):529-537.

16. Goldberg JF, Garno JL. Development of posttraumatic stress disorder in adult bipolar patients with histories of severe childhood abuse. J Psychiatr Res. 2005;39(6):595-601.

17. Pollack MH, Simon NM, Fagiolini A, et al. Persistent posttraumatic stress disorder following September 11 in patients with bipolar disorder. J Clin Psychiatry. 2006;67(3):394-399.

18. Strawn JR, Adler CM, Fleck DE, et al. Post-traumatic stress symptoms and trauma exposure in youth with first episode bipolar disorder. Early Interv Psychiatry. 2010;4(2):169-173. 
19. Dell'osso L, Stratta P, Conversano C, et al. Lifetime mania is related to post-traumatic stress symptoms in high school students exposed to the 2009 L'Aquila earthquake. Compr Psychiatry. 2014;55(2):357-362.

20. Freeman MP, Freeman SA, McElroy SL. The comorbidity of bipolar and anxiety disorders: prevalence, psychobiology, and treatment issues. $J$ Affect Disord. 2002;68(1):1-23.

21. Otto MW, Perlman CA, Wernicke R, Reese HE, Bauer MS, Pollack MH. Posttraumatic stress disorder in patients with bipolar disorder: a review of prevalence, correlates, and treatment strategies. Bipolar Disord. 2004;6(6):470-479.

22. Kessler RC, Sonnega A, Bromet E, Hughes M, Nelson CB. Posttraumatic stress disorder in the National Comorbidity Survey. Arch Gen Psychiatry. 1995;52(12):1048-1060.

23. Fullerton CS, Ursano RJ, Epstein RS, et al. Gender differences in posttraumatic stress disorder after motor vehicle accidents. Am J Psychiatry. 2001;158:1486-1491.

24. Kobayashi I, Delahanty DL. Gender differences in subjective sleep after trauma and the development of posttraumatic stress disorder symptoms: a pilot study. J Trauma Stress. 2013;26(4):467-474.

25. Carmassi C, Akiskal HS, Bessonov D, et al. Gender differences in DSM-5 versus DSM-IV-TR PTSD prevalence and criteria comparison among 512 survivors to the L'Aquila earthquake. J Affect Disord. 2014;160:55-61.

26. Dell'Osso L, Carmassi C, Stratta P, et al. Gender differences in the relationship between maladaptive behaviors and post-traumatic stress disorder. A study on 900 L' Aquila 2009 earthquake survivors. Front Psychiatry. 2012;3:111.

27. McLaughlin KA, Koenen KC, Friedman MJ, et al. Subthreshold posttraumatic stress disorder in the world health organization world mental health surveys. Biol Psychiatry. 2015;77(4):375-384.

28. Dell'Osso L, Shear MK, Carmassi C, et al. Validity and reliability of the Structured Clinical Interview for the Trauma and Loss Spectrum (SCI-TALS). Clin Pract Epidemiol Ment Health. 2008;4:2.

29. Dell'Osso L, Carmassi C, Rucci P, et al. A multidimensional spectrum approach to post-traumatic stress disorder: comparison between the Structured Clinical Interview for Trauma and Loss Spectrum (SCI-TALS) and the Self-Report instrument (TALS-SR). Compr Psychiatry. 2009;50(5):485-490.

30. Dell'Osso L, Armani A, Rucci P, et al. Measuring mood spectrum: comparison of interview (SCI-MOODS) and self-report (MOODS-SR) instruments. Compr Psychiatry. 2002;43(1):69-73.
31. Farley LM, DeMaso DR, D'Angelo E, et al. Parenting stress and parental post-traumatic stress disorder in families after pediatric heart transplantation. J Heart Lung Transplant. 2007;26(2):120-126.

32. Poder U, Ljungman G, von Essen L. Posttraumatic stress disorder among parents of children on cancer treatment: a longitudinal study. Psychooncology. 2008;17(5):430-437.

33. Lindahl Norberg A, Pöder U, Ljungman G, von Essen L. Objective and subjective factors as predictors of post-traumatic stress symptoms in parents of children with cancer - a longitudinal study. PLoS One. 2012;7(5):e36218.

34. Kessler RC, Berglund P, Demler O, Jin R, Merikangas KR, Walters EE. Lifetime prevalence and age-of-onset distributions of DSM-IV disorders in the National Comorbidity Survey Replication. Arch Gen Psychiatry. 2005;62(6):593-602.

35. Carmassi C, Stratta P, Massimetti G, et al. New DSM-5 maladaptive symptoms in PTSD: gender differences and correlations with mood spectrum symptoms in a sample of high school students following survival of an earthquake. Ann Gen Psychiatry. 2014;13:28.

36. Dell'Osso L, Carmassi C, Rucci P, et al. Lifetime subthreshold mania is related to suicidality in posttraumatic stress disorder. CNS Spectr. 2009; 14(5):262-266.

37. Koenen KC, Ratanatharathorn A, Ng L, et al. Posttraumatic stress disorder in the World Mental Health Surveys. Psychol Med. 2017;47(13): 2260-2274.

38. Rodenburg R, Meijer AM, Deković M, Aldenkamp AP. Family factors and psychopathology in children with epilepsy: a literature review. Epilepsy Behav. 2005;6(4):488-503.

39. Shatla R, Sayyah Hel S, Azzam H, Elsayed RM. Correlates of parental stress and psychopathology in pediatric epilepsy. Ann Indian Acad Neurol. 2011;14(4):252-256.

40. Leidy NK, Elixhauser A, Vickrey B, Means E, Willian MK. Seizure frequency and the health-related quality of life of adults with epilepsy. Neurology. 1999;53(1):162-166.

41. Duffy LV. Parental coping and childhood epilepsy: the need for future research. J Neurosci Nurs. 2011;43(1):29-35.

42. Dunn MJ, Rodriguez EM, Barnwell AS, et al. Posttraumatic stress symptoms in parents of children with cancer within six months of diagnosis. Health Psychol. 2012;31(2):176-185.
Neuropsychiatric Disease and Treatment

\section{Publish your work in this journal}

Neuropsychiatric Disease and Treatment is an international, peerreviewed journal of clinical therapeutics and pharmacology focusing on concise rapid reporting of clinical or pre-clinical studies on a range of neuropsychiatric and neurological disorders. This journa is indexed on PubMed Central, the 'PsycINFO' database and CAS,

\section{Dovepress}

and is the official journal of The International Neuropsychiatric Association (INA). The manuscript management system is completely online and includes a very quick and fair peer-review system, which is all easy to use. Visit http://www.dovepress.com/testimonials.php to read real quotes from published authors. 